\title{
Third Stage of Labor and Acupuncture
}

\author{
Ivka Djakovic, MD, Zeljko Djakovic, $\mathrm{MD}^{2}$, Nada Bilić, $\mathrm{MD},{ }^{3}$ and Vesna Košec, $\mathrm{PhD}^{1}$
}

\begin{abstract}
Background: Acupuncture use in obstetrics has been increasing in Western medicine, especially to alleviate complications of pregnancy, the most important cause of maternal mortality worldwide. One quarter of maternal deaths are caused by complications in the third stage of labor, an interval between complete delivery of the baby and the complete expulsion of the placenta.

Methods: This review analyzes the increased acupuncture use for pregnancy complications as a potential method of reducting maternal mortality during the third stage of labor. This overview focuses on acupuncture points and techniques to manage the third stage of labor and help patients with retained placentas. Passive (or expectant) management of the third stage of labor is occasionally associated with massive obstetric hemorrhage, a major cause of maternal morbidity and mortality, especially in low-income countries.

Conclusions: Active management of the third stage of labor has been shown to reduce the risk of postpartum hemorrhage. Use of acupuncture in the first and second stages of labor could lead to a faster separation of the placenta in the third stage of labor. The possible effects of acupuncture in cases of retained placentas may have significant implications for possible complications and final outcomes of labor. Further studies are needed for more conclusive results.
\end{abstract}

Key Words: Third Stage of Labor, Acupuncture, Retained Placenta, Postpartum Hemorrhage

\section{INTRODUCTION}

C OMPLICATIONS OF PREGNANCY are the most significant causes of maternal mortality worldwide. ${ }^{1}$ The American College of Obstetricians and Gynecologists reported in 1998 that $\sim 500,000$ women die annually across the world from causes related to pregnancy and childbirth. Onequarter of the cases are caused by complications in the third stage of labor, ${ }^{2}$ an interval between delivery of the neonate and expulsion of the placenta. ${ }^{3}$

After childbirth, the uterus begins to contract rapidly because of a loss of internal pressure. Retraction of uterine muscles occurs, uterine muscle fibers become shorter, and the uterus wall thickens. As the placental blood vessels snap, bleeding in the retroplacental space begins. ${ }^{4} \mathrm{~A}$ retro- placental hematoma divides the placenta from the uterus and exfoliates the placenta completely. ${ }^{5}$ The placenta then descends into the lower uterine segment, the vagina. This causes pressure on the cervical ganglia and nerve endings around the rectum, and the woman feels the need to push. ${ }^{6}$ The patient's active pushing facilitates spontaneous delivery of the placenta.

Passive management of the third stage of labor is occasionally associated with massive obstetric hemorrhage, a major contributor to maternal mortality in low-income countries. Active management of the third stage of labor has been shown to reduce the risk of postpartum hemorrhage. Active management of the third stage of labor involves administration of prophylactic uterotonics, early cord clamping, and controlled cord traction. ${ }^{7}$ The type of uterotonic, dose, and route

\footnotetext{
${ }^{1}$ Department of Gynecology and Obstetrics, University Hospital Center "Sestre Milosrdnice," Zagreb, Croatia.

${ }^{2}$ Department of Thoracic Surgery "Jordanovac", University Hospital Center Zagreb, Jordanovac, Zagreb, Croatia.

${ }^{3}$ Department of Anesthesiology and Intensive Care, University Hospital Center "Sestre Milosrdnice," Zagreb, Croatia.
} 
of administration vary across the globe and may have an impact on maternal outcomes. ${ }^{8}$ For example, in India only $10 \%$ of all deliveries are managed actively in the third stage of labor. ${ }^{9}$

Uterotonic agents are usually applied with assisted delivery of the placenta. ${ }^{10}$ The most commonly used uterotonic agents include oxytocin, ergometrine, prostaglandin analogues, and misoprostol. ${ }^{11-15}$ Controlled cord traction, which must be gradual and constant, can be used to assist placental delivery. ${ }^{16}$ This procedure reduces the incidence of postpartum hemorrhage and the need for manual removal of the placenta. Controlled cord traction may also shorten the duration of the third stage of labor. ${ }^{17,18}$ If placental delivery is not initially achieved, this procedure can be repeated several times. The bladder should be emptied for any manipulation of the uterus.

The mean duration of the third stage of labor is $\sim 6$ minutes. The median duration of an actively managed third stage of labor is 5 minutes. ${ }^{19,20}$ Inspection of the delivered placenta is of great importance. Manual removal of the avulsed cotyledon must be performed if retained placental tissue is detected. ${ }^{21}$ The placenta is considered to be retained if it remains undelivered 30 or 60 minutes after delivery of the neonate and following active or physiologic management of the third stage of labor. Retained placenta is a major cause of severe postpartum hemorrhage ${ }^{22}$ and has an incidence rate of $0.5 \%-3 \% .^{23-25}$ When a patient has an undelivered placenta, manual removal must be performed under general or regional anesthesia. This procedure can be complicated by intrauterine palpation, infection, or trauma to the cervix or vagina. There is also a risk related with the use of anesthesia. ${ }^{19}$

For all these reasons, a constant effort is made to implement an alternative method for retained placenta. Several reports indicate that acupuncture would be a safe, cheap and effective method to treat this condition.

\section{ACUPUNCTURE USE IN THE THIRD STAGE OF LABOR}

Women have traditionally been frequent users of complementary therapies. These women's use of such therapies continues during pregnancy and birth. The use of acupuncture in obstetrics has increased in Western medicine. ${ }^{26,27}$ A number of indications for acupuncture are accepted by the World Health Organization, the British Medical Association, and the National Institutes of Health. These indications are: alleviation of nausea and vomiting in pregnancy ${ }^{28}$; acupunctural anaesthesia; prepartal preparation; and peripartal analgesia. ${ }^{29,30}$

There are some indications of a tocolytic function of acupuncture and acupuncture correction of fetal malpresentation. ${ }^{31}$ Acupuncture in pregnancy can be used for treating all other indications for which it is used outside of pregnancy. The most frequent nonobstetric indications are: migraine; myalgia; ischialgia; carpal-tunnel syndrome; edema; sleeping disorder; constipation; and addictions, most frequently smoking. ${ }^{32-34}$. After delivery, acupuncture can be helpful during breastfeeding. ${ }^{35,36}$ One German study reported that acupuncture was used in $3.7 \%$ of all deliveries from 2001 to $2008 .^{37}$

\section{Acupuncture in the Third Stage of Labor}

There are reports of shortening the third stage of labor when acupuncture was used in the first and second stages of labor. ${ }^{26,37-41}$ This effect was explained as the result of inducing stronger and more effective contractions of the uterus when acupuncture is used.

A study from 1977, of a small sample of 32 parturients who received acupunctural anesthesia in the first and second stages of labor, reported a significantly shorter third stage of labor. ${ }^{42}$

Bader et al. compared the effect of acupuncture in three groups of women. The first group received prophylactic acupuncture at KI 16 immediately postpartum. The second group was given $3 \mathrm{IU}$ of oxytocin immediately postpartum, and the third group was not given specific therapy. The researchers concluded that the immediate postpartal prophylactic application of acupuncture at the KI16 has a clearly beneficial influence on both the duration of the third stage of labor and hemorrhage in the third stage of labor following an uncomplicated delivery. ${ }^{43}$

A large prospective multicenter randomized study conducted on 836 deliveries in Germany found no effect of any applied method for reducing the duration of the third stage of labor when applied alone or in combination with acupuncture. $^{44}$

\section{Retained Placenta}

There are many reports of successful use of acupuncture for addressing retained placenta. ${ }^{38,45}$ According to Roemer, acupuncture influences separation of placenta significantly, with success rates up to $80 \%$. In most of the cases, the placental separation occurs during the first 10 minutes. When separation of placenta did not occur after application of acupuncture, conditions such as placenta accreta, septum of the uterus, or cervical spasm occurred. Unsuccessful application of acupuncture can direct further diagnostic investigations regarding appropriateness of use under these conditions. ${ }^{46}$

Chauyan et al. analyzed 75 patients retrospectively over a 2 -years period. Acupuncture was used in 30 patients and, in 45 other patients, manual removal of the placenta was performed. In the acupuncture group, the rate of placental delivery was $83 \%$ within 20 minutes, while manual removal of the placenta was performed in $17 \%$ of these patients. No complications were noted in the acupuncture group, while the rate of complications in the second group was 6.6\%. ${ }^{47}$ This strongly supports acupuncture as an alternative method for addressing retained placenta. 
Clinical observation of acupuncture on points KI 16 and SP 6 used in healthy women who gave birth at term found spontaneous separation of the placenta in $77 \%$ of the women. However, the lack of a control group in this study does not point toward a definitive conclusion. ${ }^{48}$

Individual reports also have suggested successful use of acupuncture on points KI 16 and/or SP 6. Nonpharmacologic methods of acupuncture can be applied quickly, at low cost, and safely in third-stage labor in cases of retained placenta. Acupuncture's effect can be noted immediately. Its principal advantage would be avoiding manual exploration and complications associated with such a procedure, such as early postpartum hemorrhage, uterine atony, uterine rupture, puerperal infection, anemia, and adverse side-effects of anesthesia. ${ }^{49}$

Despite the evidence presented above, rigorous randomized studies, particularly those using objective measures, have failed to identify any obvious benefits from acupuncture for many of the other conditions studied. ${ }^{50}$

Acupuncture during labor and delivery is well-tolerated by patients and by medical staff members and practitioners who provide acupuncture delivery. ${ }^{51,52}$ In the United Kingdom, intrapartum acupuncture is usually provided by professional acupuncturists, but in countries such as Germany and Scandinavian nations, it is widely applied by midwives. ${ }^{53}$

\section{CONCLUSIONS}

In a few conducted studies promising effects of acupuncture on duration of the third stage of labor, retained placenta, and complications of the delivery were presented. These results suggest that acupuncture could be an alternative method to reduce the number of serious complications that might occur during third-stage labor, and thereby reduce maternal morbidity. For definitive conclusions, randomized controlled studies are needed.

\section{DISCLOSURE STATEMENT}

No competing financial interests exist.

\section{REFERENCES}

1. Changaee F, Simbar M, Irajpour A, Akbari S. Quality assessment of peripartum care. Iran Red Crescent Med J. 2014;16(6):e9069.

2. American College of Gynecologists (ACOG). Postpartum hemorrhage: Number 243, January 1998 (replaces No. 143, July 1990). ACOG Educational Bulletin. Int J Gynaecol Obstet. 1998;61(1):79-86.

3. Devey DE. Normal labour. In: Dewhurst CJ, ed. Integrated Obstetrics and Gynaecology. Oxford, London, Edinburgh, Melbourne: Blackwell Scientific Publications; 1972:180-206.
4. Banovic I, Roje D. Normal labour. In: Kupešić S, Đelmiš J, eds. Gynecology and Perinatology in Croatian]. Varaždinske Toplice: Tonimir; 2003:163-72.

5. MacPherson J, Wilson JK. A radiological study of the placental stage of labour. J Obstet Gynaecol Br Emp. 1956; 63(3):321-330.

6. Ivanišević M. Third stage of labor and examination of the placenta In: Kuvačić I, Kurjak A, Đelmiš J, et al., eds. Obstetrics [in Croatian]. Zagreb: Medicinska Naklada; 2009:210-215.

7. Begley CM, Gyte GM, Devane D, McGuire W, Weeks A. Active versus expectant management for women in the third stage of labour. Cochrane Database Syst Rev. 2011;11:CD007412.

8. Westhoff G, Cotter AM, Tolosa JE. Prophylactic oxytocin for the third stage of labour to prevent postpartum haemorrhage. Cochrane Database Syst Rev. 2013;10:CD001808.

9. Stanton CK, Deepak NN, Mallapur AA, et al. Direct observation of uterotonic drug use at public health facility-based deliveries in four districts in India. Int J Gynaecol Obstet. 2014;127(1):25-30.

10. Oguz Orhan E, Dilbaz B, Aksakal SE, Altinbas S, Erkaya S. Prospective randomized trial of oxytocine administration for active management of the third stage of labor. Int J Gynaecol Obstet. 2014;127(2):175-179.

11. Gülmezoglu AM, Villar J, Ngoc NT, et al. WHO multicentre randomised trial of misoprostol in the management of the third stage of labour. Lancet. 2001;358(9283):689-695.

12. Mukta M, Sahay PB. Role of misoprostol $600 \mathrm{mcg}$ oral in active management of third stage of labor: A comparative study with oxytocin $10 \mathrm{IU}$ i.m. J Obstet Gynaecol India. 2013;63(5):325-327.

13. Tewatia R, Rani S, Srivastav U, Makhija B. Sublingual misoprostol versus intravenous oxytocin in prevention of post-partum hemorrhage. Arch Gynecol Obstet. 2014;289(4): 739-742.

14. Firouzbakht M, Kiapour A, Omidvar S. Prevention of postpartum hemorrhage by rectal misoprostol: A randomized clinical trial. J Nat Sci Biol Med. 2013;4(1):134-137.

15. Sharma M, Kaur P, Kaur K, Kaur A, Kaur PK, Kaur MM. A comparative study of oxytocin/misoprostol/methylergometrine for active management of the third stage of labor. $J$ Obstet Gynaecol India. 2014;64(3):175-179.

16. Artymuk N, Surina M, Marochko T. Active management of the third stage of labor with and without controlled cord traction. Int J Gynaecol Obstet. 2014;124(1):84-85.

17. Du Y, Ye M, Zheng F. Active management of the third stage of labor with and without controlled cord traction: A systemic review and meta-analysis of randomized controlled trials. Acta Obstet Gynecol Scand. 2014;93(7):626-633.

18. Asicioglu O, Unal C, Asicioglu BB, et al. Influence of placental cord drainage in menagement of the third stage of labor: A multicenter randomized controlled study. Am J Perinatol. 2014; August 11:e-pub ahead of print.

19. Taebi M, Kalahroudi MA, Sadat Z, Saberi F. The duration of the third stage of labor and related factors. Iran J Nurs Midwifery Res. 2012;17(2[suppl1]):S76-S79.

20. Childress KM, Holloran-Schwartz BM, Wuebker H, Gavard J, Blaskiewicz R. The third stage of labor: A study of outcomes in the second trimester of pregnancy. J Reprod Med. 2014;59(7-8):348-354. 
21. Benirschke K. The placenta in the context of history and modern medical practice. Arch Pathol Lab Med. 1991;115(7): 663-667.

22. Marahatta R. Retained placenta-a major cause of maternal morbidity. Nepal Med Coll J. 2012;14(1):41-45.

23. Abdel-Aleem H, Abdel-Aleem MA, Shaaban OM. Tocolysis for management of retained placenta. Cochrane Database Syst Rev. 2011;1:CD007708.

24. Cheung WM, Hawkes A, Ibish S, Weeks AD. The retained placenta: Historical and geographical rate variations. J Obstet Gynaecol. 2011;31(1):37-42.

25. Weeks AD. The retained placenta. Best Pract Res Clin Obstet Gynaecol. 2008;22(6):1103-1117.

26. Smith C, Dahlen H. Caring for the pregnant woman and her baby in a changing maternity service environment: The role of acupuncture. Acupunct Med. 2009;27(3):123-125.

27. Hope-Allan N, Adams J, Sibbritt D, Tracy S. The use of acupuncture in maternity care: A pilot study evaluating the acupuncture service in an Australian hospital antenatal clinic. Complement Ther Nurs Midwifery. 2004;10(4):229-232.

28. Matthews A, Haas DM, O'Mathuna DP, Dowswell T, Doyle M. Interventions for nausea and vomiting in early pregnency. Cochrane Database Syst Rev. 2014;3:CD007575.

29. Smith CA, Cochrane S. Does acupuncture have a place as an adjunct treatment during pregnancy? A review of randomized controlled trials and systematic reviews. Birth. 2009;36(3): 246-253.

30. Harper TC, Coeytaux RR, Chen W, et al. A randomized controlled trial of acupuncture for initiation of labor in nulliparous women. J Matern Fetal Neonatal Med. 2006;19(8): 465-470.

31. Neri I, Airola G, Contu G, Allais G, Facchinetti F, Benedetto C. Acupuncture plus moxibustion to resolve breech presentation: A randomized controlled study. J Matern Fetal Neonatal Med. 2004;15(4):247-252.

32. Ewies AA, Olah KS. The sharp end of medical practice: The use of acupuncture in obstetrics and gynaecology. BJOG. 2002;109(1):1-4.

33. Lythgoe J. Getting needled! Pract Midwife. 2013;16(8):S6-S9.

34. Manber R, Schnyer RN, Allen JJ, Rush AJ, Blasey CM. Acupuncture: A promising treatment for depression during pregnancy. J Affect Disord. 2004;83(1):89-95.

35. Habek D. Clinical use of acupuncture in gynecology, obstetrics and reproductive medicine [in Croatian]. Gynecol Perinatol. 2001;10(suppl1):138-144.

36. Soliday E, Hapke P. Characteristics of a U.S. obstertric acupuncture clinic patient sample. Explore (N Y). 2014;10(2); 109-114.

37. Münstedt K, Thienel J, Hrogovic I, Hackethal A, Kalder M, Misselwitz B. Use of acupuncture and other CAM methods in obstetrics: An analysis of 409,413 deliveries from Hesse, Germany. J Altern Complement Med. 2011;17(5):421-426.

38. Chen Y, Zhang X, Fang Y, Yang J. Analyzing the study of using acupuncture in delivery in the past ten years in China. Evid Based Complement Alternat Med. 2014;2014:672508.
39. Dong $\mathrm{C}, \mathrm{Hu} \mathrm{L}$, Liang $\mathrm{F}$, Zhang $\mathrm{S}$. Effects of electroacupuncture on labor pain management. Arch Gynecol Obstet. 2014;August 20:e-pub ahead of print.

40. Cui JM, Ma SX, Jin ZH, Dong LH. Effect of moxibustion at Sanyinjiao (SP 6) on delivery stage and postpartum bleeding of primipara [in Chinese]. Zhongguo Zhen Jiu. 2011;31(10): 898-900.

41. Zhu L, Yang F, Jin CL, et al. Effect of electroacupuncture at different frequencies on serum estradiol and progesterone levels in late-stage pregnancy rats [in Chinese] Zhen Ci Yan Jiu. 2012;37(4):281-285.

42. Hyodo M, Gega O. Use of acupuncture anesthesia for normal delivery. Am J Chin Med (Gard City N Y). 1977;5(1):63-69.

43. Bader W, Ast S, Hatzmann W. The significance of acupuncture in the third stage of labour [in German]. German $J$ Acupunct. 2000;43(4):264-268.

44. Koettnitz F, Wübbeke S, Krick M, et al. Acupuncture for placenta solution? [in German]. Geburtsh Frauenheilk. 1999; 59(11):562-565.

45. Mårtensson L, Kvint LJ, Hermansson E. A national survey of how acupuncture is currently used in midwifery care at Swedish maternity units. Midwifery. 2011;27(1):87-92.

46. Roemer A. Acupuncture for midwives, obstetricians and gynecologists. In: Textbook of Chinese Medicine [in German]. Stuttgart, Germany; 2013:140.

47. Chauhan PA, Gassef F, Chauhan A. Clinical investigation on the use of acupuncture for treatment of placental retention. Am J Acupunct. 1998;26(1):19-25.

48. Djakovic I, Bilic N. Acupuncture for retained placenta: A retrospective case series. Acupunct Med. 2014;32(6):506-508.

49. Bobic MV, Habek D. Treatment of retained placenta with acupuncture. Int J Gynaecol Obstet. 2012;116(1):80.

50. Xu J, MacKenzie IZ. The current use of acupuncture during pregnancy and childbirth. Curr Opin Obstet Gynecol. 2012; 24(2):65-71.

51. Citkovitz C, Klimenko E, Bolyai M, Applewhite L, Julliard $\mathrm{K}$, Weiner Z. Effects of acupuncture during labor and delivery in a U.S. hospital setting: A case-control pilot study. J Altern Complement Med. 2009;15(5):501-505.

52. Liu YL, Jin ZG. Clinical observation of the impacts and safety of electrocupuncture at Sanyinjiao (SP 6) on labor [in Chinese]. Zhongguo Zhen Jiu. 2012;32(5):409-412.

53. Carr D, Lythgoe J. Use of acupuncture during labour. Pract Midwife. 2014;17(5):10,12-15.

Address correspondence to: Ivka Djakovic, $M D$

Department of Gynecology and Obstetrics University Hospital Center "Sestre Milosrdnice",

Vinogradska street 29 10000 Zagreb Croatia

E-mail:ivkadj@yahoo.com 